\title{
Indicators of opinion leadership in customer networks: self-reports and degree centrality
}

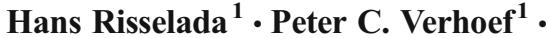 \\ Tammo H. A. Bijmolt ${ }^{1}$
}

Published online: 28 April 2015

(C) The Author(s) 2015. This article is published with open access at Springerlink.com

\begin{abstract}
In this paper, we assess two alternative indicators of opinion leadership, selfreported opinion leadership and degree centrality, on the same dataset. We also investigate the interaction effect of these two indicators and the social network environment on opinion leadership. We use social network and survey data from the mobile telecom industry to analyze opinion leadership in smartphone adoption. We find that degree centrality indicates opinion leadership, but that self-reported opinion leadership indicates opinion leadership only under the right social circumstances. In case of weak to moderate network ties, the effect of self-reported opinion leadership is not significant. However, self-reported opinion leaders more effectively influence their strong ties. This study sheds light on indicators of opinion leadership and provides insights for managers to improve their social marketing campaigns.
\end{abstract}

Keywords Social network data Opinion leadership · Adoption

\section{Introduction}

A large body of research supports the impact of social influence, i.e., customers affect the behavior of others in their social network (e.g., Giudicati et al. 2013; Haenlein 2011; Nitzan and Libai 2011). What remains unclear is how to assess opinion leadership or disproportionate social influence (Godes 2011). Its accurate assessment is

Hans Risselada

H.Risselada@rug.nl

Peter C. Verhoef

P.C.Verhoef@rug.nl

Tammo H. A. Bijmolt

T.H.A.Bijmolt@rug.nl

1 Faculty of Economics and Business, Department of Marketing, University of Groningen,

P.O. Box 800, NL-9700 AV Groningen, The Netherlands 
imperative for successful implementation of social network marketing campaigns (e.g., viral campaigns).

Previous literature suggests two types of indicators of opinion leadership suitable for large customer networks, namely objective measures based on network characteristics (e.g., degree centrality) and subjective measures based on self-reports (Van den Bulte 2010). Multiple studies have shown that network characteristics are related to opinion leadership (Delre et al. 2010; Katona et al. 2011). There is less evidence for selfreported opinion leadership as an indicator (Eck Van et al. 2011; Kratzer and Lettl 2009). In particular, it is unclear to what extent self-reported opinion leadership is an indicator of opinion leadership over and above the network characteristics. Furthermore, little is known about whether and how these two indicators and the consumer's position in the network may jointly indicate opinion leadership.

In this study, we empirically investigate opinion leadership among customers of a mobile telecom operator. We constructed a dataset consisting of network and survey data enabling us to investigate both network characteristics and self-reported opinion leadership as indicators of opinion leadership in smartphone adoption. We infer social networks from mobile phone communication patterns and opinion leadership from observed behavior.

This study has two main contributions. First, we assess two alternative indicators of opinion leadership on the same dataset. Second, we investigate the interaction effect of these two indicators and the social network environment on a customer's opinion leadership. Surprisingly, we show that there is a significant positive simple effect of degree centrality but no significant simple effect of self-reported opinion leadership on actual opinion leadership. However, we provide evidence for the interaction between self-reported opinion leadership and the social environment; self-reported opinion leaders more effectively influence their strong ties. In sum, we show that traditional self-designation techniques and the recently popular social network metrics jointly indicate a customers' opinion leadership.

Our insights are particularly relevant for marketers aiming to exploit opinion leadership for marketing purposes. We show that identifying opinion leaders in a customer base requires data on the individual customer and on the social environment the customer is in. Marketers can use our results to assess the influence of customers more accurately and thereby improve the seeding and planning of social marketing campaigns.

\section{Theoretical background}

\subsection{Indicators of opinion leadership}

We study two alternative indicators of opinion leadership, self-reported opinion leadership, and degree centrality. Opinion leaders are defined as consumers that exert a disproportionate influence on those around them (King and Summers 1970). If properly assessed, self-reported opinion leadership should by definition be positively related to opinion leadership. Degree centrality is the number of others with whom a customer has a relationship. Influencing others in your network takes effort. This implies that when a customer's network is larger, the available effort per person may be smaller 
(e.g., Katona et al. 2011; Leskovec et al. 2007). However, degree centrality is also an indicator of a customer's status, which is positively related to opinion leadership (Hu and Van den Bulte 2014). Given that a smartphone is a high-technology and visible product, we expect that status considerations may play a large role.

\subsection{The social network environment}

We also account for the effects of social network variables. Social influence on customer behavior may occur through increasing awareness and through belief updating (Van den Bulte and Wuyts 2007, p. 39). Adoption of an innovative and expensive and thus risky product like the smartphone requires probably more than just being made aware of the existence of the product. The strength of weak ties theory suggests that for "just" creating awareness, weak ties would be superior. However, we expect that the spread of adoption behavior (and thus belief updating) of risky products requires a stronger relationship because it is not just the structure of the network that matters but also the nature of the relationship between adopter and potential follower (Centola and Macy 2007).

Another network variable we account for is homophily. Homophily is the phenomenon that people tend to associate with others like them (McPherson et al. 2001). Similar people are likely to behave similarly (Van den Bulte and Wuyts 2007; Nitzan and Libai 2011). In this sense, homophily is a competing explanation for similarities in observed behavior among connected individuals. However, customers may be more likely to trust customers with similar preferences and mainly share experiences with customers like themselves. This could foster social influence. We control for follower characteristics and homophily, but we will not be able to fully disentangle these two phenomena.

\subsection{Interplay between the indicators of opinion leadership and the social environment}

We expect that opinion leadership may depend on the social environment. Stronger ties, with a higher communication frequency, allow for more opportunities for influence to be exerted. This suggests that self-reported opinion leaders and those with a high degree centrality are more influential over strong ties.

Based on the discussion above, we expect that self-reported opinion leadership and degree centrality are both indicators of opinion leadership that affects adoption. Furthermore, we expect stronger relations between the two indicators and opinion leadership when ties are stronger.

\subsection{Control variables}

We examine the influence of a customer who adopted as the first in his/her network (the initiator) on the adoption of another customer in his/her ego network (the follower). We are interested in the relationship of network characteristics and self-reported opinion leadership with opinion leadership and in the interactions between the two. We control for a number of characteristics of the initiator and the follower to disentangle opinion leadership from the intrinsic likelihood to adopt. Furthermore, we account for the 
characteristics of the potential follower by including gender, service usage (follower), relationship length, and direct marketing (e.g., Prins and Verhoef 2007) as control variables. To control for the type of initiator, we include the time of adoption and personal characteristics of the initiator, i.e., commitment and involvement, in the model.

\section{Data}

In this study, we empirically investigate opinion leadership in the mobile telecom industry. We used three sources of data: call detail records (CDR), a customer database, and an online survey. We started the data collection with a set of respondents of an online survey on a representative sample of the customer base of a large Dutch telecom operator in December 2010. We identified those respondents that were the first in their ego network to adopt a smartphone (the initiators). We used the CDR data of MayJune 2010 to create ego networks for the initiators $\left(n_{\text {initiators }}=1994, n_{\text {potentialfollowers }}=\right.$ 6373 ) and collected monthly adoption data in January 2009-February 2011. ${ }^{1}$ The number of months between initiator and follower adoptions ranges from 1 to 20, with a mean of 9.6 and a standard deviation of 5.8. We use definitions for a tie and its strength from prior work (Nitzan and Libai 2011; Onnela et al. 2007). A tie is based on reciprocal contact between two individuals. We measure tie strength by communication volume, i.e., the number of calling minutes plus the number of text messages. Degree centrality of the initiator is defined as the number of direct relationships (Van den Bulte and Wuyts 2007, p. 20). ${ }^{2}$ Figure 1 gives a first impression of the relationship between the two indicators of opinion leadership. It shows that for low values of self-reported opinion leadership degree centrality is also low, but that for larger values of selfreported opinion leadership it becomes less diagnostic for degree centrality. This pattern is in line with the findings of Iyengar et al. (2011a). We measure homophily based on age, gender, education level, and income, where similarity on each of these variables adds 0.25 to the homophily score (Brown and Reingen 1987; Nitzan and Libai 2011). Age is considered to be similar if the difference is smaller than or equal to 5 years. We mean-centered and log-transformed tie strength and mean-centered degree centrality and homophily for the analyses. The variable usage refers to the usage intensity of mobile telecom services and is measured as the average monthly revenue of a customer.

The telecom industry is well suited for social influence research because network data can be obtained and linked to behavioral data (e.g., Nitzan and Libai 2011; Risselada et al. 2014). Family calling plans were not available at this telecom operator

\footnotetext{
${ }^{1}$ Adoption of a smartphone could lead to endogenous tie formation because consumers get their new phone from a new provider and would start using the phone for calling friends with this same provider (assuming that calling plans with same-provider-discounts exist). However, we study adoption among existing customers of the telecom operator only which makes this type of tie formation unlikely. Another argument in favor of endogenous tie formation would be that a smartphone enables customers to communicate in new ways by, for example, web-based services like WhatsApp or Facebook. However, in line with existing work (e.g., Nitzan and Libai (2011)), the ties in our study are based on calling and texting behavior. See the Robustness check section for an empirical check on this issue.

${ }^{2}$ Due to confidentiality issues, we are not allowed to share details on degree centrality and communication volume (i.e., tie strength).
} 


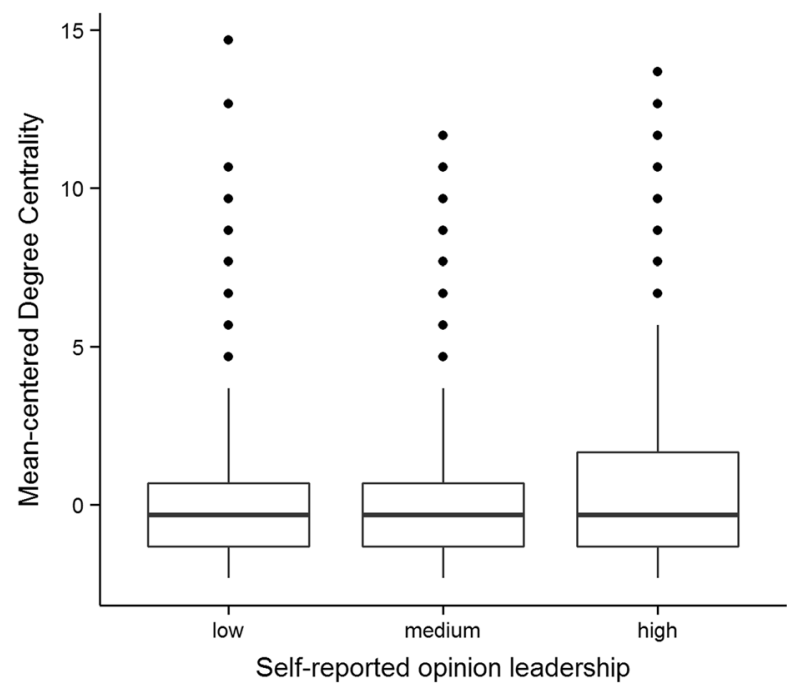

Fig. 1 Degree centrality versus self-reported opinion leadership

during the observation period. Therefore, it is likely that customers make independent decisions and no group decision making takes place.

\subsection{Survey}

We conducted an online survey in December 2010 to collect the individual characteristics of the initiators. We worked closely together with the firm to be able to include our questions in a larger customer survey. For self-reported opinion leadership and the control variables commitment and involvement, we adapted existing scales to reduce the length of the survey and increase the expected response rate. Existing literature shows that opinion leadership is a broad concept and several authors argue that innovativeness and perceived knowledge are part of the broad opinion leadership construct (Kratzer and Lettl 2009). Therefore, we measured self-reported opinion leadership using two items on persuasiveness from the scale by Flynn et al. (1994), three items on innovativeness (Goldsmith and Hofacker 1991; Steenkamp and Gielens 2003), and two items on perceived knowledge (Flynn and Goldsmith 1999; Pritchard et al. 1999). Table 1 presents an overview of the items we used and the papers in which they have been developed and used.

We used a principal component analysis (PCA) to examine the factor structure. A three-factor solution is consistent with the theoretical constructs; the variance explained is larger than $70 \%$, and three eigenvalues are larger than 1 (Hair et al. 2010). The first factor represents self-reported opinion leadership (SROL; Cronbach's $\alpha=0.88$ ). Factor 2 corresponds with the scale of commitment $(\alpha=0.89)$ and Factor 3 with the scale of involvement ${ }^{3}$ (correlation coefficient $=0.61$ ). We use the factors from the PCA model as variables in our models; all PCA factors have mean 0 and standard deviation 1 . Tables 2 and 3 show the correlations of initiator and follower level variables, respectively.

\footnotetext{
${ }^{3}$ We also performed a confirmatory factor analysis (CFA) to assess the validity of the three latent factors. The fit measures indicate that the CFA model fits the data well (RMSAE $=0.11, \mathrm{CFI}=0.94, \mathrm{SRMR}=0.049)$.
} 
Table 1 Items used in the survey

\begin{tabular}{|c|c|c|}
\hline Construct & Items & Adaptations from... \\
\hline $\begin{array}{l}\text { Opinion leadership_- } \\
\text { persuasiveness }\end{array}$ & $\begin{array}{l}\text { 1. When they choose a mobile phone, other } \\
\text { people turn to me for advice (pers } 1 \text { ) } \\
\text { 2. I often persuade others to buy the mobile } \\
\text { phones that I like (pers } 2 \text { ) }\end{array}$ & $\begin{array}{l}\text { Flynn et al. } 1994 \\
\text { Kratzer and Lettl } 2009\end{array}$ \\
\hline $\begin{array}{l}\text { Opinion leadership- } \\
\text { innovativeness }\end{array}$ & $\begin{array}{l}\text { 3. In general, I am the first in my circle of friends } \\
\text { to buy a new mobile phone when it appears (innov1) } \\
\text { 4. If I heard that a new mobile phone was available, } \\
\text { I would be interested enough to buy it (innov2) } \\
\text { 5. I like to buy a new mobile phone before other } \\
\text { people do (innov3) }\end{array}$ & $\begin{array}{l}\text { Goldsmith and } \\
\text { Hofacker } 1991 \\
\text { Steenkamp and } \\
\text { Gielens } 2003\end{array}$ \\
\hline $\begin{array}{l}\text { Opinion leadership- } \\
\text { perceived knowledge }\end{array}$ & $\begin{array}{l}\text { 6. I belong to the } 25 \% \text { of the population that knows } \\
\text { the most about mobile products/services (perck1) } \\
\text { 7. I consider myself to be an educated consumer } \\
\text { regarding mobile telephony (perck2) }\end{array}$ & $\begin{array}{l}\text { Pritchard et al. } 1999 \\
\text { Heitmann et al. } 2007 \\
\text { Flynn and Goldsmith } \\
\quad 1999\end{array}$ \\
\hline Commitment & $\begin{array}{l}\text { 8. I feel XYZ knows what I want (commit1) } \\
\text { 9. I feel a strong sense of belonging to XYZ (commit2) } \\
\text { 10. I feel a strong sense of attachment to XYZ (commit3) }\end{array}$ & Verhoef 2003 \\
\hline Involvement & $\begin{array}{l}\text { 11. Generally, I am someone who finds it important } \\
\text { what mobile products/services he or she buys (involv1) } \\
\text { 12. Generally, I am someone who is interested in the kind } \\
\text { of mobile products/services he or she buys (involv2) }\end{array}$ & De Wulf et al. 2001 \\
\hline
\end{tabular}

\section{Method}

We model the timing of the behavior of a potential follower in the ego network of an initiator and thereby assess the effects of self-reported opinion leadership and degree centrality. We assume that if the time between the adoptions of the initiator and follower is shorter, opinion leadership of the initiator is larger. The model is based on the hazard model that is typically used to model time-to-event data (Franses and Paap 2001). The hazard is the probability that the event of interest will take place in the next period given that it did not occur yet. We use the complementary log-log formulation because adoption is a continuous process that we analyze on a monthly interval basis. We estimate a multilevel version of the hazard model because the ego network of an initiator typically contains multiple potential followers (Barber et al. 2000). We

Table 2 Correlations among initiator level variables

(1)

1.000

Time of adoption (1)

Degree centrality (2)

Commitment (3)

Involvement (4)

SROL (5)
$-0.277^{* * *}$

$-0.024$

$-0.063^{* *}$

$-0.120^{* * *}$
(2)

(3)

(4)

(5)

${ }^{*} p<0.05 ; * * p<0.01 ; * * * p<0.001$

$\begin{array}{llr}1.000 & & \\ 0.057^{*} & 1.000 & \\ 0.005 & -0.003 & 1.000 \\ 0.055^{*} & 0.002 & -0.005\end{array}$


Table 3 Correlations among follower level variables

(1)

AVG_direct marketing (1)

Service usage (2)

Relationship length (3)

Tie strength (4)

Homophily (5)
(2)

(3)

(4)

\subsection{0}

$-0.007 \quad 1.000$

$0.102 * * * \quad-0.021$

1.000

$-0.028 * \quad 0.084 * * * \quad-0.028^{*}$

$\begin{array}{llll}-0.027^{*} & -0.026^{*} & -0.014 & 0.089^{* * *}\end{array}$

1.000

1.000

${ }^{*} p<0.05 ;{ }^{* *} p<0.01 ; * * * p<0.001$

specifically apply a nonparametric baseline hazard by including monthly dummies. Equation (1) shows the complementary log-log formulation of the hazard model, and Eqs. (2) and (3) show the individual and ego network level of the linear part of the model. The hazard $h_{i j t}$ of potential follower $i$ in the ego network of initiator $j$ in month $t$ (after the adoption of the initiator) is defined as:

$$
h_{i j t}=1-\exp \left[-\exp \left[x^{(i j t)} \beta\right]\right] \text {. }
$$

Individual level

$$
\begin{aligned}
& x^{(i j t)} \beta=\beta_{0 j t}+\beta_{1 j} \text { tie_strength }_{i j}+\beta_{2 j} \text { homophily }_{i j}+\beta_{3 j} \text { usage }_{i}+\beta_{4 j} \mathrm{AVG}_{-} \text {direct_marketing } \\
&+\beta_{5 j} \text { direct_marketing }_{i t}+\beta_{6 j} \text { gender_male }_{i}+\beta_{7 j} \text { relationship_length } \\
& i
\end{aligned}
$$

Ego network level

$$
\begin{aligned}
\beta_{0 j t}= & \gamma_{00}+\gamma_{01} \text { Month } 2+\ldots+\gamma_{024} \text { Month } 25+\gamma_{025} \text { degree_centrality }_{j}+\gamma_{026} \mathrm{SROL}_{j} \\
& +\gamma_{027} \text { commitment }_{j}+\gamma_{028} \text { involvement }_{j}+\gamma_{029} \text { conitiator }_{j}+\gamma_{030}\left(\text { tie_strength }_{i j} \times \mathrm{SROL}_{j}\right) \\
& +\gamma_{031}\left(\text { tie_strength }_{i j} \times \text { degree_centrality }_{j}\right)+\nu_{0 j}
\end{aligned}
$$

and

$$
\beta_{1 j}=\gamma_{10}, \beta_{2 j}=\gamma_{20}, \beta_{3 j}=\gamma_{30}, \beta_{4 j}=\gamma_{40}, \beta_{5 j}=\gamma_{50}, \beta_{6 j}=\gamma_{60}, \beta_{7 j}=\gamma_{70}
$$

We apply a Mundlak approach to account for the potential endogeneity of direct marketing. More specifically, we include the average number of DMs per week a customer receives during the observation period (AVG_direct_marketing) as an additional variable (Risselada et al. 2014). The average number of DMs per week is a proxy for how likely it is that a customer receives a DM. Hence, the Mundlak approach accounts for between-subject differences in potential effectiveness of $\mathrm{DM}$, and the relevant DM parameter now captures within-subject effects. By including this variable, we aim to take out the correlation between the error term and the remaining DM covariate. We include a Gaussian frailty term in the model $\left(\nu_{0 j} \sim \mathcal{N}\left(0, \Omega_{\nu}\right)\right)$ to account for unobserved heterogeneity on the initiator level. 


\section{Results}

Table 4 presents the estimation results of the smartphone adoption models. We estimate two versions of the model. The Main model is the complete model with all variables included. The Copula model is the model with additional variables which capture potential endogeneity in the self-reported variables by means of the Copula approach described by Park and Gupta (2012). One of the key advantages of that approach is that it does not require an exclusion restriction (Park and Gupta 2012, p. 567). Endogeneity or reverse causality may be present because we collected the survey data during the observation period of the adoptions. However, the results of the Main model show that the simple effect of self-reported opinion leadership is not significant, which reduces our concern for this endogeneity issue. The additional Copula variables are indicated by the addition "star" to the variable name. None of the Copula variables is significant, so we only discuss the results of the Main model.

\subsection{Effects of self-reported opinion leadership and degree centrality}

The simple effect of self-reported opinion leadership (for average tie strength) is positive, but not significant $\left(\gamma_{026}=0.029, p=0.197\right)$. This result is not in line with our expectations. We find a positive and significant effect of degree centrality $\left(\gamma_{025}=0.019\right.$, $p=0.010$ ), which implies that if the ego network of the initiator is larger, the influence on a single potential follower is greater. This result supports our expectation. Finally, the results of the control variables, including homophily are in line with previous research.

\subsection{Interactions with tie strength}

We find a positive significant simple effect of tie strength $\left(\gamma_{10}=0.036, p=0.039\right)$. This implies that social influence is greater over stronger relationships (for customers with an average self-reported opinion leadership score), which supports our expectations. The interaction of tie strength and self-reported opinion leadership (TSxSROL) is positive and significant at the $10 \%$ level $\left(\gamma_{030}=0.028, p=0.064\right)$. This result supports our expectation on the moderating effect of tie strength. Surprisingly, the interaction of tie strength and degree centrality is not significant $\left(\gamma_{031}=0.000, p=0.961,\right)^{4}$

For the sake of interpretation of the significant interaction effect of the indicator tie strength and self-reported opinion leadership, we plotted the total effect of the indicator on the utility against the range of observed values of tie strength in Fig. 2. Figure 2 shows that the effect of self-reported opinion leadership is positive and significant for values of tie strength above 0.72 , which holds for $31 \%$ of the observations.

\footnotetext{
${ }^{4}$ To check whether the results suffer from severe multicollinearity due to the presence of two interactions, we also estimated two separate models with only one interaction in each model. The results are substantively the same. The main difference is that the tie strength $\times$ SROL interaction becomes significant at the $5 \%$ level. Complete results can be requested from the first author.
} 
Table 4 Estimation results

\begin{tabular}{|c|c|c|c|c|c|c|}
\hline & \multicolumn{3}{|l|}{ Main model } & \multicolumn{3}{|c|}{ Copula model } \\
\hline & Estimate & s.e. & $p$ & Estimate & s.e. & $p$ \\
\hline Intercept & -9.895 & 0.339 & $<0.001$ & -9.906 & 0.340 & $<0.001$ \\
\hline \multicolumn{7}{|l|}{ Initiator characteristics } \\
\hline Time of adoption (initiator) & 0.015 & 0.006 & 0.006 & 0.015 & 0.006 & 0.006 \\
\hline Involvement & 0.043 & 0.023 & 0.066 & 0.094 & 0.140 & 0.504 \\
\hline Involvementstar & & & & -0.053 & 0.141 & 0.704 \\
\hline Commitment & 0.054 & 0.021 & 0.010 & 0.279 & 0.329 & 0.397 \\
\hline Commitmentstar & & & & -0.221 & 0.328 & 0.500 \\
\hline \multicolumn{7}{|l|}{ Follower characteristics } \\
\hline Gender $(1=$ male $)$ & -0.107 & 0.043 & 0.013 & -0.106 & 0.043 & 0.013 \\
\hline Relationship length & 0.527 & 0.026 & $<0.001$ & 0.528 & 0.026 & $<0.001$ \\
\hline Service usage & 0.448 & 0.034 & $<0.001$ & 0.448 & 0.034 & $<0.001$ \\
\hline Direct marketing & 0.532 & 0.113 & $<0.001$ & 0.533 & 0.113 & $<0.001$ \\
\hline AVG_direct_marketing & 0.015 & 0.005 & 0.007 & 0.015 & 0.005 & 0.007 \\
\hline \multicolumn{7}{|l|}{ Indicators of opinion leadership } \\
\hline Self-reported opinion leadership (SROL) & 0.029 & 0.023 & 0.197 & -0.066 & 0.163 & 0.683 \\
\hline SROLstar & & & & 0.095 & 0.164 & 0.562 \\
\hline Degree centrality & 0.019 & 0.007 & 0.010 & 0.020 & 0.008 & 0.008 \\
\hline \multicolumn{7}{|l|}{ Network characteristics } \\
\hline Tie strength & 0.036 & 0.018 & 0.039 & 0.036 & 0.018 & 0.041 \\
\hline Homophily & 0.295 & 0.082 & $<0.001$ & 0.297 & 0.083 & 0.000 \\
\hline \multicolumn{7}{|l|}{ Interactions } \\
\hline Tie strength $\times \mathrm{OL}$ & 0.028 & 0.015 & 0.064 & 0.034 & 0.062 & 0.578 \\
\hline Tie strength $\times$ OLstar & & & & -0.010 & 0.091 & 0.912 \\
\hline Tie strength $\times$ degree centrality & 0.000 & 0.004 & 0.961 & 0.000 & 0.004 & 0.956 \\
\hline$\sigma_{v}$ & 0.192 & 0.379 & & 0.192 & 0.387 & \\
\hline Loglikelihood (LL) & -9718.657 & & & -9717.126 & & \\
\hline
\end{tabular}

We left out the estimates for the monthly dummies for the sake of clarity

\subsection{Robustness check on endogenous tie formation}

There could be an issue with endogenous tie formation as a result of the timing of our network data collection. To check whether this is indeed the case, we created a dummy variable indicating whether an initiator adopted before or after the moment of network data collection (Dpost; $0=$ adoption before network data collection, $1=$ adoption after network data collection). If endogenous tie formation were present, ties would have been formed as a result of an adoption and therefore the real effect of degree centrality would be overestimated in case of initiator adoption before the network data collection. We included the dummy Dpost and the interaction between Dpost and degree centrality (DC) in the model. Both parameters are not significant $\left(\beta_{\text {Dpost }}=-0.072, p=0.610\right.$; 


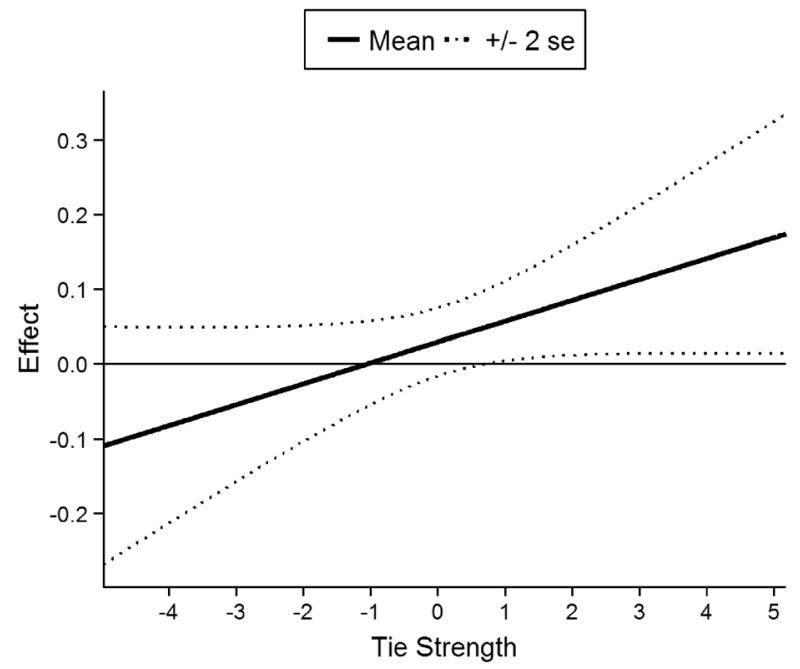

Fig. 2 Interaction effect of tie strength and self-reported opinion leadership

$\left.\beta_{\text {intDpostDC }}=0.066, p=0.192\right)$ which shows that the effect of degree centrality is not significantly different before and after network data collection. This suggests that endogenous tie formation is not a major issue here. ${ }^{5}$

\section{Discussion}

Marketers have high expectations regarding the use of social networks and influence as a marketing tool. Despite the large body of research on opinion leadership, it remains unclear how to assess it. Recent work addressed social network characteristics as indicators of opinion leadership (e.g., Katona et al. 2011; Nitzan and Libai 2011). In this study, we argue that opinion leadership is related to a combination of the social environment and the degree of self-reported opinion leadership of a customer. More specifically, we investigate self-reported opinion leadership and degree centrality as alternative indicators of opinion leadership and we investigate potential interactions between the indicators and tie strength.

We find that degree centrality has a positive simple effect on opinion leadership and is thus a useful indicator of opinion leadership. In contrast, we find that self-reported opinion leadership has little to no effect on opinion leadership if tie strength is low to moderate. This is surprising because by definition, opinion leaders should exert a disproportionate influence on others (King and Summers 1970). This finding complements the work by Iyengar et al. (2011b) which shows that opinion leaders are less susceptible to influence from others, but that this relationship does not hold for sociometric leaders. We provide evidence which supports their suggestion that selfreported opinion leadership may signal self-confidence instead of actual opinion leadership. Self-reported opinion leaders think that they affect the behavior of others, but this is not what we observe in behavioral data.

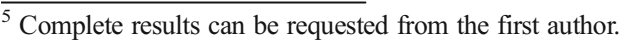


However, we also show that opinion leaders have exceptional influence under the right social circumstances. That is, self-reported opinion leaders are most influential via their strong ties. One explanation could be that self-reported opinion leaders target their influence at their strong ties. Those strong tie contacts are more exposed to the selfreported opinion leader and thus more likely to follow his/her behavior, whereas the reverse holds for weak ties. In sum, opinion leadership is a combination of a customer's social environment and self-reported opinion leadership.

\section{Research limitations}

This study has several limitations. First, we limited ourselves to the analysis of ego networks of the initiators because we did not have access to full network data. Most followers will be connected to other customers of which we have no data. We implicitly assume that adoption is determined by the follower's characteristics and the influence exerted by the initiator. More specifically, we assume that the unobserved potential influencers are nonsystematically affecting the behavior of the followers.

Second, we measure tie strength using frequency of interaction but ignore the second dimension valence (Van den Bulte and Wuyts 2007, p. 16). Using both dimensions would provide a better description of the network, but the data do not allow us to measure valence. We note that our measure is in line with other studies using similar data (Nitzan and Libai 2011; Onnela et al. 2007).

Acknowledgments This research is supported by MSI research grant \#4-1706.

We thank Marnik Dekimpe, David Godes, Peter Leeflang, Christophe Van den Bulte, and Stefan Wuyts for their constructive comments on earlier versions of this paper.

Open Access This article is distributed under the terms of the Creative Commons Attribution 4.0 International License (http://creativecommons.org/licenses/by/4.0/), which permits unrestricted use, distribution, and reproduction in any medium, provided you give appropriate credit to the original author(s) and the source, provide a link to the Creative Commons license, and indicate if changes were made.

\section{References}

Barber, J. S., Murphy, S. A., Axinn, W. G., \& Maples, J. (2000). Discrete-time multilevel hazard analysis. Sociological Methodology, 30(1), 201-35.

Brown, J. J., \& Reingen, P. H. (1987). Social ties and word-of-mouth referral behavior. Journal of Consumer Research, 14(3), 350-62.

Centola, D., \& Macy, M. (2007). Complex contagions and the weakness of long ties. American Journal of Sociology, 113(3), 702-34.

De Wulf, K., Odekerken-Schroder, G., \& Iacobucci, D. (2001). Investments in consumer relationships: a cross-country and cross-industry exploration. Journal of Marketing, 65(4), 33-50.

Delre, S. A., Jager, W., Bijmolt, T. H. A., \& Janssen, M. A. (2010). Will it spread or not? The effects of social influences and network topology on innovation diffusion. Journal of Product Innovation Management, 27(2), 267-82.

Eck Van, P. S., Jager, W., \& Leeflang, P. S. H. (2011). Opinion leaders' role in innovation diffusion: a simulation study. Journal of Product Innovation Management, 28(2), 187-203.

Flynn, L. R., \& Goldsmith, R. E. (1999). A short, reliable measure of subjective knowledge. Journal of Business Research, 46(1), 57-66. 
Flynn, L. R., Goldsmith, R. E., \& Eastman, J. K. (1994). The king and summers opinion leadership scale: revision and refinement. Journal of Business Research, 31(1), 55-64.

Franses, P. H., \& Paap, R. (2001). Quantitative models in marketing research. Cambridge, UK: Cambridge University Press.

Giudicati, G., Riccaboni, M., \& Romiti, A. (2013). Experience, socialization and customer retention: lessons from the dance floor. Marketing Letters, 24(4), 409-22.

Godes, D. (2011). Commentary-invited comment on 'opinion leadership and social contagion in new product diffusion'. Marketing Science, 30(2), 224-29.

Goldsmith, R., \& Hofacker, C. (1991). Measuring consumer innovativeness. Journal of the Academy of Marketing Science, 19(3), 209-21.

Haenlein, M. (2011). A social network analysis of customer-level revenue distribution. Marketing Letters, 22(1), 15-29.

Hair, J. F., Black, W. C., Babin, B. J., Anderson, R. E., \& Tatham, R. L. (2010). Multivariate data analysis: a global perspective. Upper Saddle River: Pearson Education.

Heitmann, M., Lehmann, D. R., \& Herrmann, A. (2007). Choice goal attainment and decision and consumption satisfaction. Journal of Marketing Research, 44(2), 234-50.

Hu, Y., \& Van den Bulte, C. (2014). Nonmonotonic status effects in new product adoption. Marketing Science, 33(4), 509-33.

Iyengar, R., Van den Bulte, C., Eichert, J., West, B., \& Valente, T. W. (2011a). How social networks and opinion leaders affect the adoption of new products. GfK Marketing Intelligence Review, 3(1), 16-26.

Iyengar, R., Van den Bulte, C., \& Valente, T. W. (2011b). Opinion leadership and social contagion in new product diffusion. Marketing Science, 30(2), 195-212.

Katona, Z., Zubcsek, P. P., \& Sarvary, M. (2011). Network effects and personal influences: the diffusion of an online social network. Journal of Marketing Research, 48(3), 425-43.

King, C. W., \& Summers, J. O. (1970). Overlap of opinion leadership across consumer product categories. Journal of Marketing Research, 7(1), 43-50.

Kratzer, J., \& Lettl, C. (2009). Distinctive roles of lead users and opinion leaders in the social networks of schoolchildren. Journal of Consumer Research, 36(4), 646-59.

Leskovec, J., Adamic, L. A., \& Huberman, B. A. (2007). The dynamics of viral marketing. ACM Transactions on the Web, 1(1), 228-37.

McPherson, M., Smith-Lovin, L., \& Cook, J. M. (2001). Birds of a feather: homophily in social networks. Annual Review of Sociology, 27(1), 415-44.

Nitzan, I., \& Libai, B. (2011). Social effects on customer retention. Journal of Marketing, 75(6), 24-38.

Onnela, J.-P., Saramäki, J., Hyvönen, J., Szabó, G., Lazer, D., Kaski, K., Kertész, J., \& Barabási, A.-L. (2007). Structure and tie strengths in mobile communication networks. Proceedings of the National Academy of Sciences, 104(18), 7332-36.

Park, S., \& Gupta, S. (2012). Handling endogenous regressors by joint estimation using copulas. Marketing Science, 31(4), 567-86.

Prins, R., \& Verhoef, P. C. (2007). Marketing communication drivers of adoption timing of a new E-service among existing customers. Journal of Marketing, 71(2), 169-83.

Pritchard, M. P., Havitz, M. E., \& Howard, D. R. (1999). Analyzing the commitment-loyalty link in service contexts. Journal of the Academy of Marketing Science, 27(3), 333-48.

Risselada, H., Verhoef, P. C., \& Bijmolt, T. H. A. (2014). Dynamic effects of social influence and direct marketing on the adoption of high-technology products. Journal of Marketing, 78(2), 52-68.

Steenkamp, J.-B. E. M., \& Gielens, K. (2003). Consumer and market drivers of the trial probability of new consumer packaged goods. Journal of Consumer Research, 30(3), 368-84.

Van den Bulte, C. (2010). Opportunities and challenges in studying customer networks. In S. Wuyts, M. G. Dekimpe, E. Gijsbrechts, \& R. Pieters (Eds.), The connected customer: the changing nature of consumer and business markets (pp. 7-35). London: Routledge.

Van den Bulte, C., \& Wuyts, S. (2007). Social networks and marketing, MSI relevant knowledge series. Cambridge: Marketing Science Institute.

Verhoef, P. C. (2003). Understanding the effect of customer relationship management efforts on customer retention and customer share development. Journal of Marketing, 67(4), 30-45. 